\title{
Detailed Study on Tunnel Construction Techniques at DMRC
}

\author{
Suhail Ahmad Ahanger \\ Email Id: suhail.nit87@gmail.com \\ Department of Civil Engineering, Islamic University of Science and Technology, Awantipora.
}

\begin{abstract}
The paper presents a detailed study on the tunnel construction using TBM (Tunnel Boring Machine). The paper presents a detailed description of the procedures and methods employed for the construction of Tunnels in DMRC (Delhi Metro Rail corporation). The methods employed for excavation of the tunnels and lining of the tunnels are discussed briefly. The working of tunnel boring machine for excavation and the properties of the lining materials is reviewed in this paper.
\end{abstract}

Keywords- Tunnel Boring Machine; DMRC; Lining of tunnels; excavation of tunnel.

\section{INTRODUCTION:}

The Delhi Metro is a rapid transit system serving Delhi and its satellite cities of Bahadurgarh, Ballabhgarh, Faridabad, Ghaziabad, Gurgaon and Noida in the National Capital Region of India. By far the largest and busiest metro in India and second oldest after the Kolkata Metro. It covers network about $327 \mathrm{kms}$ and covering about 236 stations[1] .The DMRC( Delhi Metro Rail Corporation ) is the first railway project in the world that has been certified by the UN to get carbon credits for reducing the Green House Gas emissions .It has reduced pollution in the city by 6.3 lakh tons every year ,thus helping in reducing the carbon footprint [2].The tunnels constructed in the DMRC Project are constructed with the help of tunnel boring machines (TBM) .The use of TBM reduces the time of completion of the tunnels .The TBM excavates the tunnel sections through a variety of rock strata and soft strata and causes minimum disturbances to the surrounding soil strata ..The TBM excavations are usually preferred in the area where there is absence of fault lines.

Construction phases: The construction of tunnel through TBM involves the following steps:

(a) Excavation of tunnel section with the help of TBM (Tunnel Boring Machine). (b) Casting of concrete segments for lining the tunnel.

(c) Assembling and fixing of tunnel segments at site.

\section{EXCAVATION:}

The tunnels in the Delhi Metro are excavated with the help of Tunnel Boring machine (TBM). The advantages of TBM over other methods of excavations are, limited disturbances to the surrounding soils and producing smooth tunnel wall. The TBM consists of rotating cutting wheel called a cutter head followed by main bearing a thrust system and trailing support system. The selection of TBM for excavation of tunnels is due to the presence of relatively soft stratum of soil at site. For the purpose of excavation of tunnel a deep trench is made at one end of the tunnel and the head of the TBM is lowered into the trench .The cutting edge of the TBM is made to rest against the proposed tunnel section and then TBM is started .The disc cutters create compressive stress fractures in the hard rock or soil causing it to fall off from the tunnel face .The excavated material is transported to the outside with the help of trailing system, which consists of conveyor belts on which the tunnel muck or the excavated material is carried outside the tunnel. 


\section{Available online at www.ijrat.org}
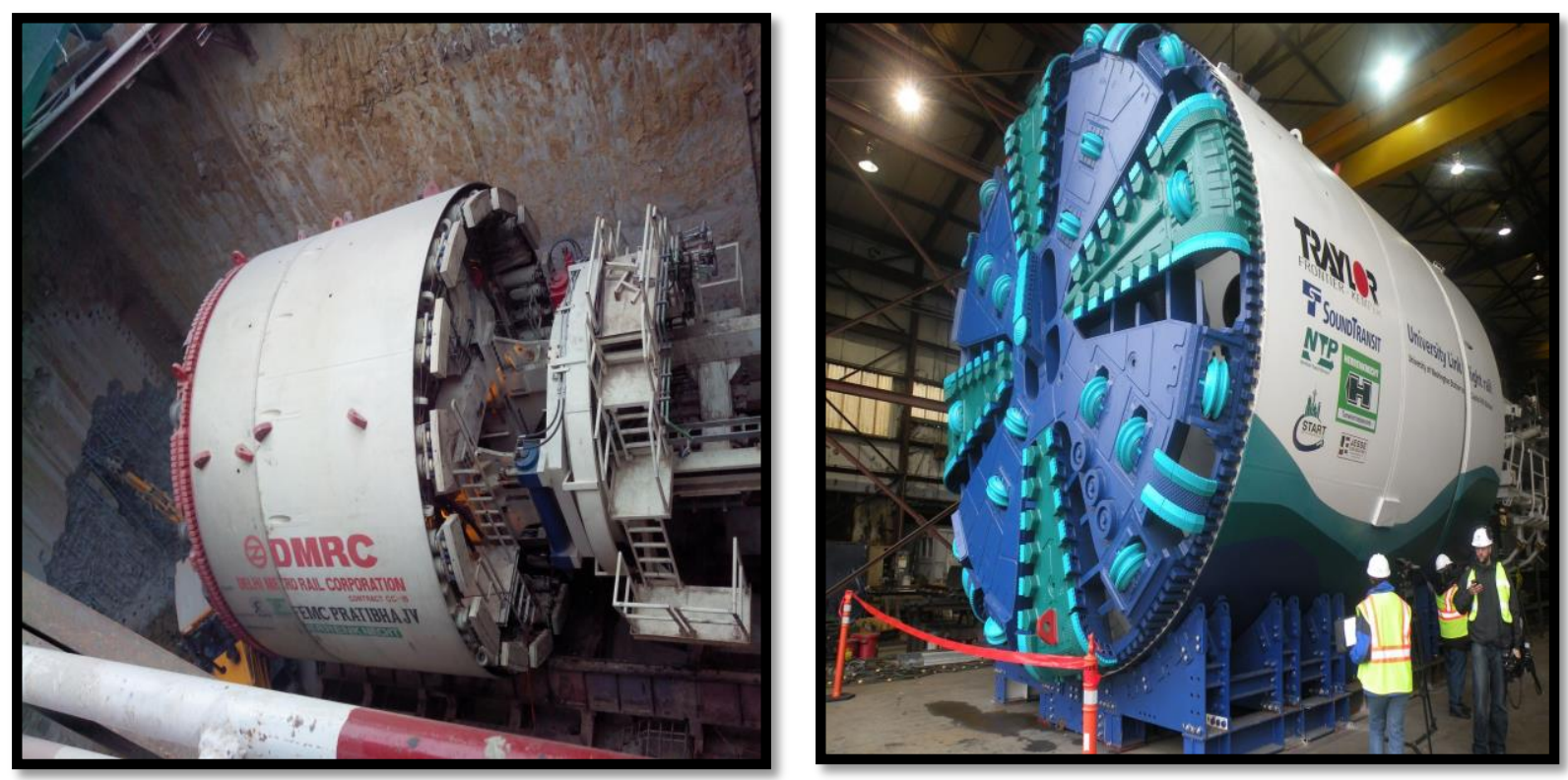

Figure 1: TBM at DMRC(L)and cutting head of TBM (R)

The TBM cutter heads are provided with series of foam injection points with nozzles on the face of the cutter wheel, a pair of nozzles are also provided in the screw conveyor for assisting in preventing or overcoming blockages. The excavations are controlled by the operator so as to minimize any risk of surface settlement. Adequate earth pressure balance in the mixing chamber behind the cutting wheel is maintained and the quantity of spoil being removed during each advance cycle is monitored closely. Earth pressure is maintained mainly through the screw conveyor balancing discharge with advance rate, torque and RPM.

The TBM cutter head consists a total of 96 face picks (cutting Knives), and 6 No. $\times 17$-inch disc cutters at its periphery. All the face picks or cutters are designed to facilitate being changed from within the cutter head. A single extendable gauge scraper is provided which is remotely operated by the TBM operator to facilitate additional overcut during the driving curves.[3]

\section{LINING OF EXCAVATED TUNNEL SECTION:}

The tunnel section needs to be lined after excavation, in order to prevent the soil from falling back into the section. The excavated tunnel segment is lined by concrete segments which help in holding the soil back and also takes the load of the soil column above it. The operation of tunnel lining involves the casting of pre cast concrete segments at the casting yard, transportation of tunnel lining segments from the casting yard to the site and assembling of concrete segments at the site.

\section{Casting of pre cast concrete segments:}

The pre cast concrete segment used for lining the tunnel section are casted at the casting yard. The concrete segments are reinforced concrete segments with steel as the main reinforcing element. The concrete that is used for casting the tunnel segments is prepared in the batching plants conforming to IS 4926.The capacity of the batching plant that is used for batching the concrete is $30 \mathrm{~m}^{3} / \mathrm{hr}$. [2] The materials used for casting concrete segments consists of high yield steel deformable bar of Fe 500 D conforming to IS 1786: 2008, concrete conforming to IS 456: 2000, water, micro silica conforming to ASTM C-1240, fly ash conforming to IS 3812-1.

The tunnel lining consists of five different types of segments and one key (S1). The five segments are named as S2, S3, S4, S4 and S6. Thus one complete ring of covering the tunnel sections consists of five segments and one key. 

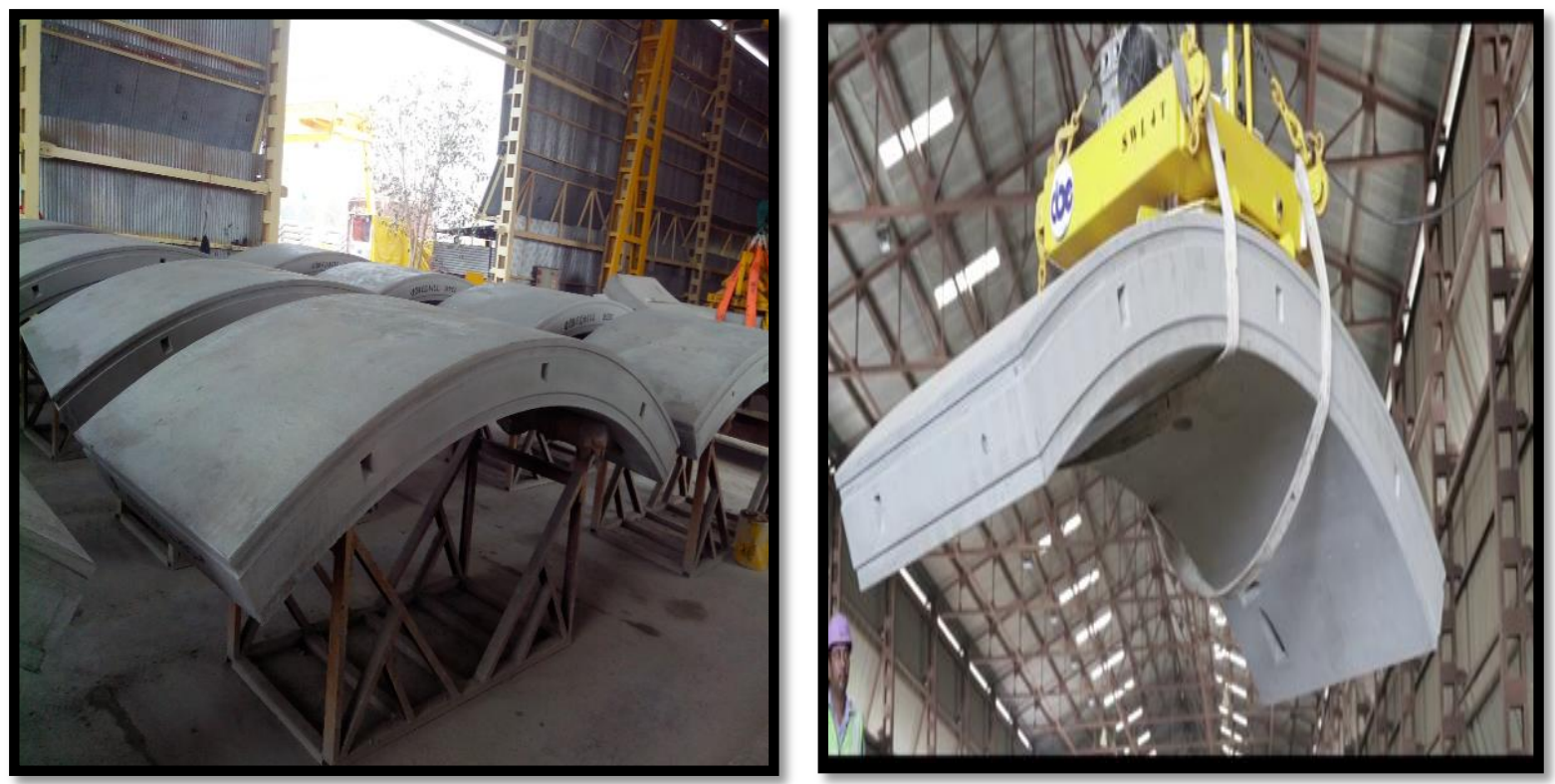

Figure 2: Concrete segment for tunnel lining (L) and lifting of concrete segment from casting bed to repair area

The Jigs are used for fabrication of reinforcement cages for tunnel lining segments. Steel reinforcement is bent and placed in jigs at the production facility to ensure its accuracy and correct positioning as mentioned in the drawings. The different parts of the reinforcement is welded with the help of MIG welding using suitable size of electrode conforming to IS 9417:1989 at specific locations to make it form and rigid.[4]
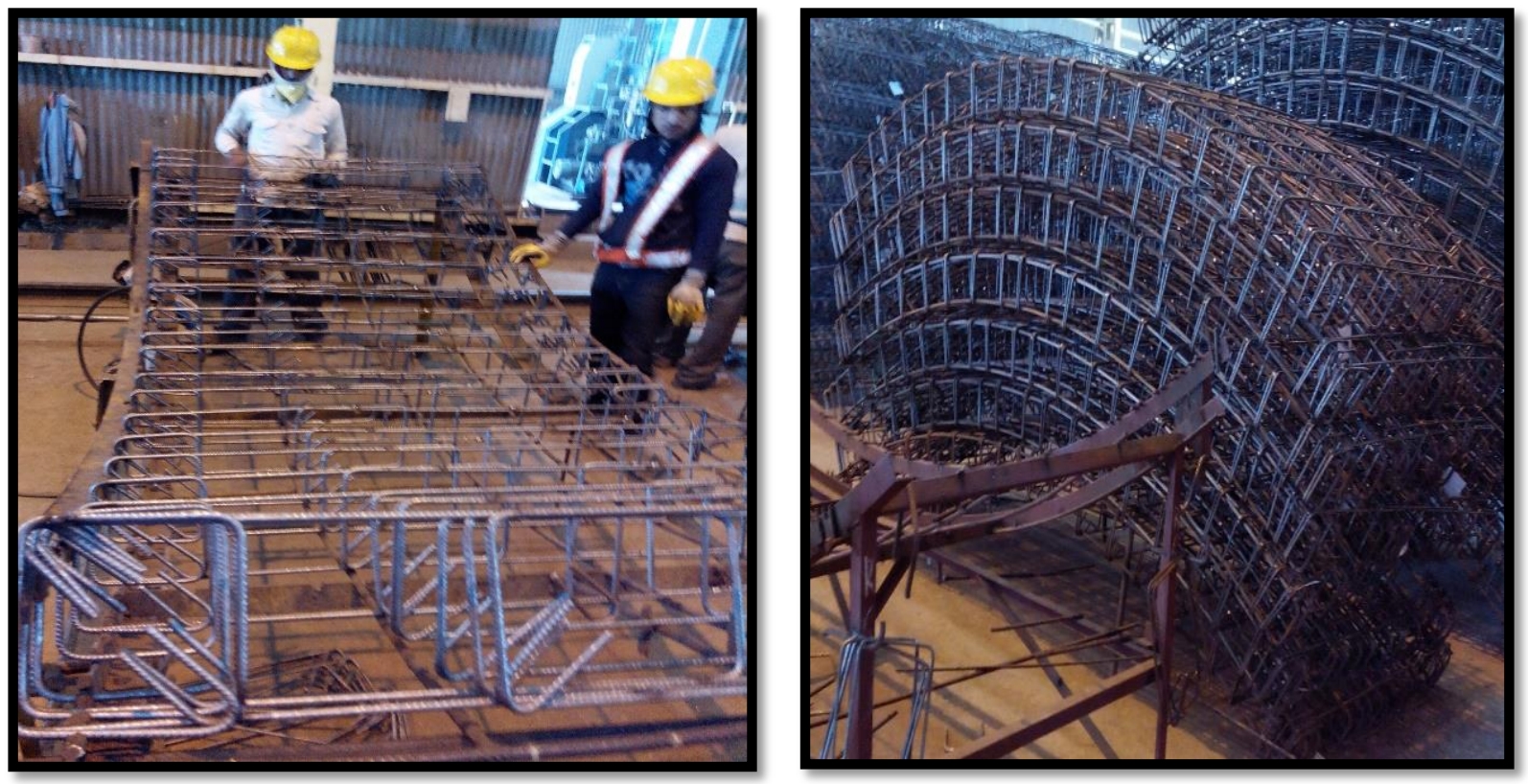

Figure 3: Reinforcement in a jig machine (L) and reinforcement cage for tunnel segments (R)

For casting the segment ,the reinforcement prepared in the jig is placed in the segment mould and after fixing the reinforcement in the mould properly, the concrete is poured into the mould .The PVC spacers are used and 


\section{International Journal of Research in Advent Technology, Vol.7, No.2, February 2019 E-ISSN: 2321-9637 \\ Available online at $w w w . i j r a t . o r g$}

attached to the main bar of the steel cage at specific locations in order to control the concrete cover to the rebar.The concrete is poured with the means of extendable chutes of concrete mixer into the moulds .The concrete is placed continuously in the layers over the full width of the mould .During the placement of the concrete compaction is constantly applied by shutter vibrators to minimize the occurrence of honeycombing or segregation problem.After the compaction of the concrete and the initial set of concrete, the mould cover is opened .After final finishing of surfaces the concrete segments are subjected to curing .The concrete segments are covered with plastic sheets to prevent the loss of moisture from the segments .

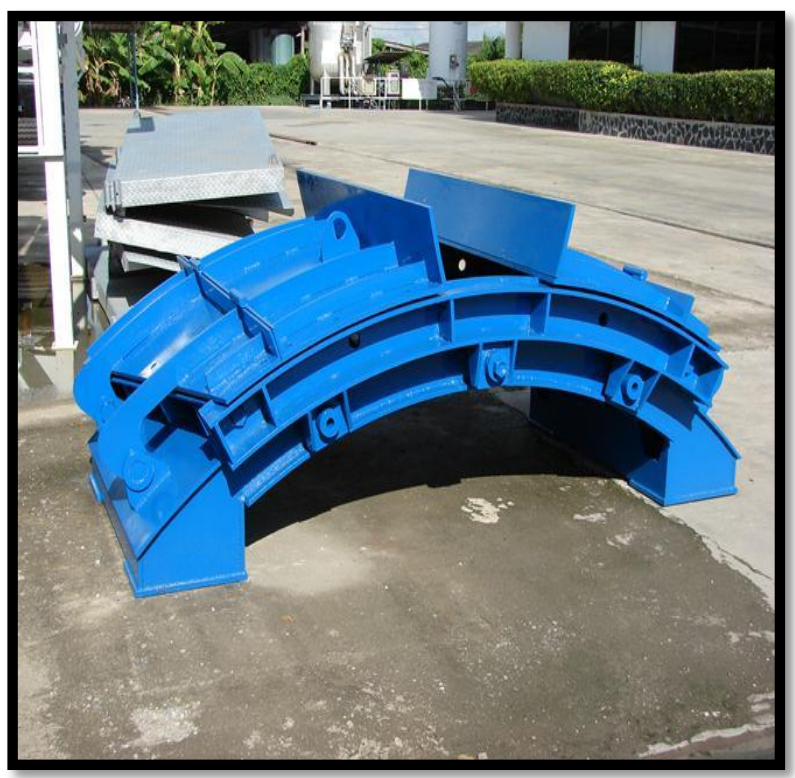

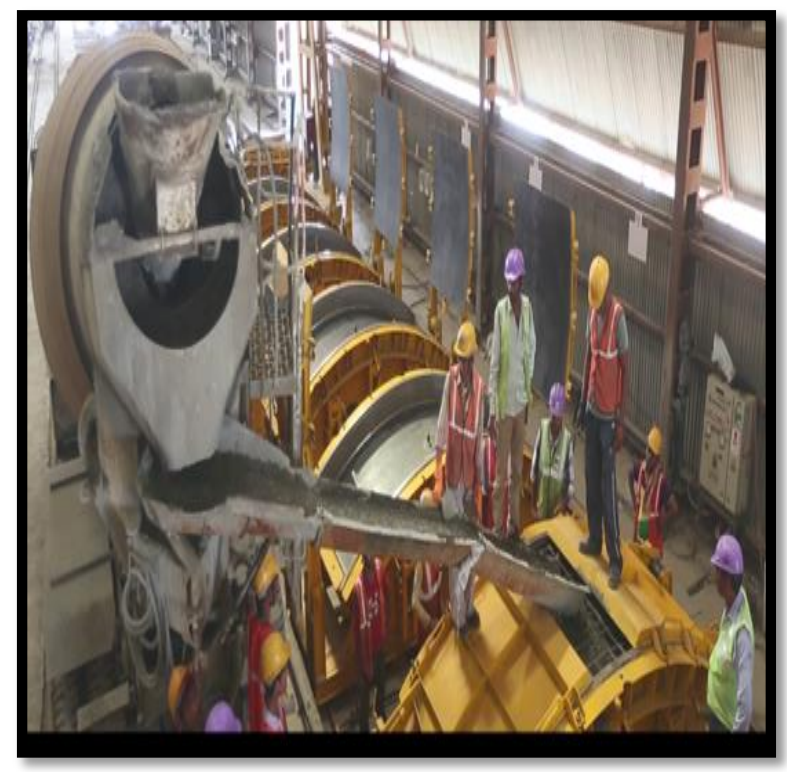

Figure 4: Tunnel segment Mould (L) and pouring of concrete into the segment Mould (R)

The concrete segments are subjected to two types of curing at the casting yard to achieve the desired strength.

Moist Curing: In this type of curing, the segments are covered with plastic sheets to evade any loss of moisture. On achieving the desired strength the segments are removed from the mould and are lifted from the casting bed by vacuum demoulding device and transported to repair area by crane.

Steam Curing: As an alternative to moist curing, in order to keep the delivery time an optimum storage rate, steam curing is used to reduce the curing time. The above process is done in following two steps

Preset (Phase I) : Pre set period is given to concrete after casting to ensure that the surface gets hardened and to avoid any thermal shocks and cracks. The pre set is generally taken as 02 hours.

Steam curing (Phase II): Immediately after the completion of pre set period (phase I), the steam chamber is closed and from all side the application of steam is started to increase the temperature of the chamber $60^{\circ} \mathrm{C}$ at the rate not exceeding $22^{\circ} \mathrm{C} / \mathrm{hr}$. The temperature inside the chamber is maintained for the period of $1.5 \mathrm{Hrs}$. After $1.5 \mathrm{hrs}$ of constant temperature, the supply of steam is stopped and the segment is allowed to cool down. Care is taken to ensure that the rate of decrease in temperature is not more than $22^{\circ} \mathrm{C} / \mathrm{hr}$. [4] 


\section{Available online at www.ijrat.org}

The concrete moulds after achieving the required compressive strength is transported to repair area by vacuum demolding device. The repair of concrete segments involves checking for blow holes, edge and corner damage, surface damage and recess damage. This procedure defines the extent of damages in the concrete mould.

\section{Storage and transportation of concrete segments:}

The segments are shifted from the shed area with the help of sling and gantry crane kept on segment car and shifted to storage area. A maximum of two segments are rested on wooden battens placed with intrados face upwards are lifted at a time. The segments are stacked horizontally at the storage yard with intrados face upwards by sling belt, the segments are stacked with one ring high and supported by timber battens $90 \mathrm{~mm} \times$ $90 \mathrm{~mm}$ section at storage area to prevent cracks from arising with the self-weight of the segments.[4]

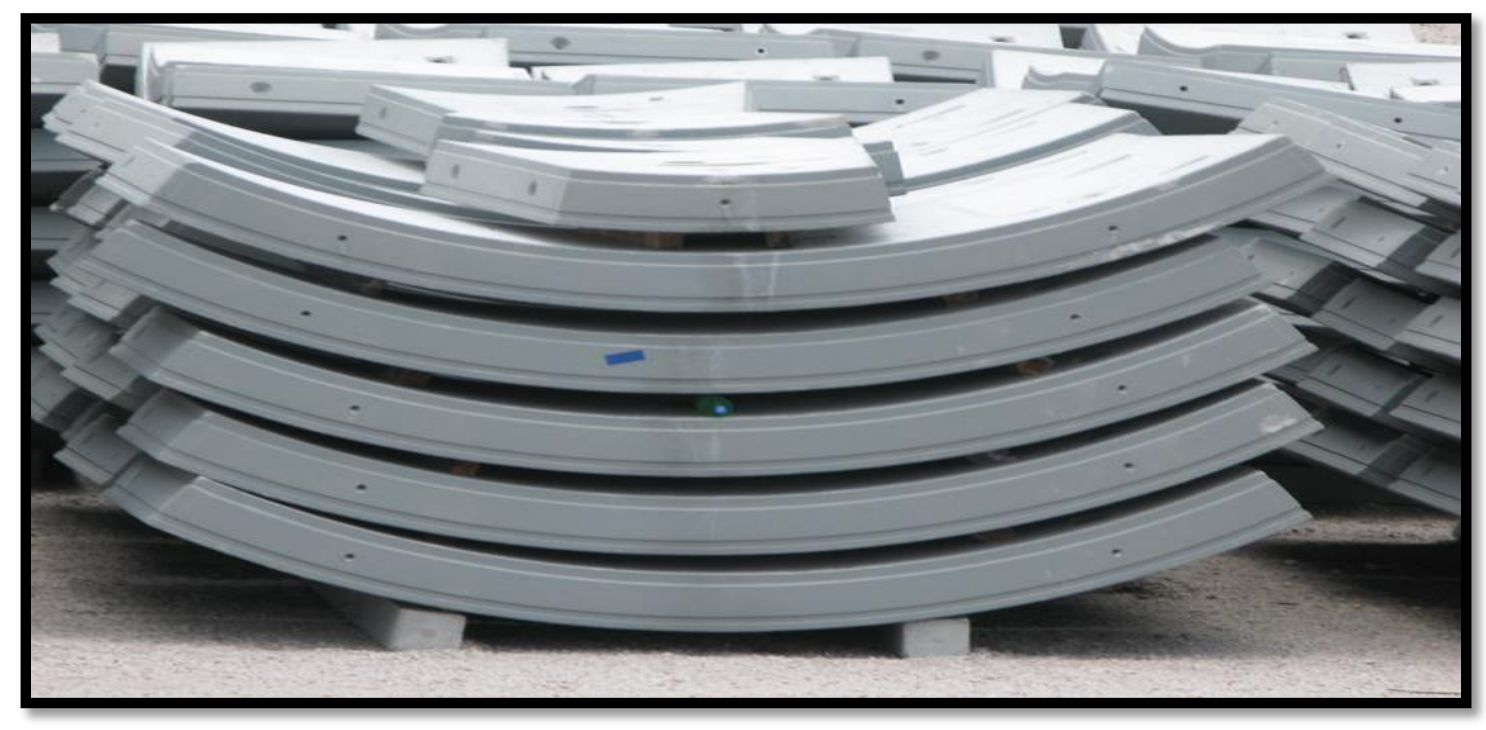

Figure 5: Storage of concrete segments

\section{Transportation of concrete segments:}

The segments are transported and stacked horizontally from the casting yard to the tunnel site. The concrete segments are placed very carefully in the lorry and the concrete segments are separated by wooden battens in the lorry so as to prevent any cracks or damages in the concrete segments. Each lorry transports two rings each delivery that is 10 segments and two keys (S1).

\section{ASSEMBLING AND FIXING THE TUNNEL SEGMENTS AT SITE:}

The concrete segments are assembled at the tunnel site with the help of bolts. The tunnel segments are transported into the tunnel with the help of supply train which brings the segments to the front of the machine. The segments are rotated in place with the help of erector arms. Bolts and dowels are used to align the segments and attach them to each other. The tunnels are lined in the form of rings or one complete circle. One ring of segments consists of five segments and one key which are joined together by high strength bolts in staggered position. 


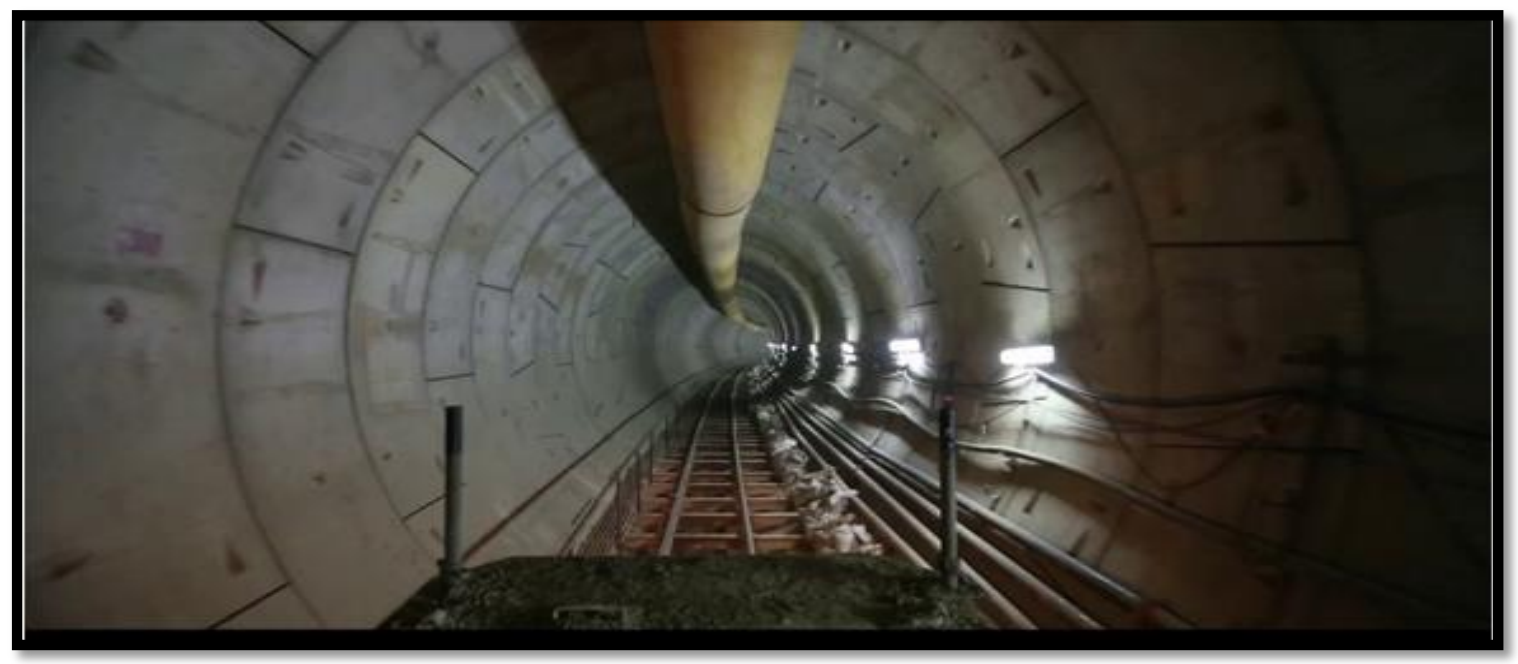

Figure 6: Assembled tunnel segments in a tunnel.

\section{CONCLUSION}

In this research paper, the detailed procedure for construction of tunnels with the help of TBM (Tunnel Boring Machine) has been discussed. The paper presents a broad overview of the methodologies used in the excavation of tunnel sections, lining of the tunnel sections with the help of concrete segments ,casting of the tunnel lining segments ,their transportation from the casting yard to the tunnel site and assemblage of segments for final lining of the tunnel section.

\section{ACKNOWLEDGEMENTS:}

This work reported here was conducted during the internship with DMRC( Delhi Metro Rail Corporation).The author would like to thank all the technical staff of DMRC who were involved in the execution work. The Author is specially thankful to Er.Shivam Sahu and Er.Raghuveer Singh Tomar for their guidance throughout the internship period.

\section{REFERENCES:}

[1] Delhi Metro Rail Corporation ,DMRC, www.delhimetrorail.com.

[2] Rahul Goel, Geetam Tiwari (2014) ,Promoting Low carbon Transport in India, UNEP ,centre on energy ,climate and sustainable development.

[3] Method statement for TBM Tunneling operations, document no.9014/ FEMCP/MS/C/026(00)

[4] Method statement for production, transportation of pre cast concrete segmental tunnel lining, CC 18 project of DMRC. 